\title{
PHASE-SENSITIVE RADIO-EGHO SOUNDING AT THE DEVON ISLAND ICE CAP, CANADA
}

\author{
By M. E. R. Walford, P. C. Holdorf and R. G. Oakberg \\ (H. H. Wills Physics Laboratory, University of Bristol, Bristol BS8 ITL, England)
}

\begin{abstract}
A radio-echo sounder has been built with which both the amplitude and phase of radio echoes can be measured. In experiments with this instrument at the Devon Island ice cap, in the Canadian Northern Territories, precise amplitude and phase measurements have been made upon radio echoes from the bed of the ice cap. If these measurements are repeated after a number of years, the results, considered in conjunction with snow accumulation and compaction data, will be interpretable as a long-term change in the thickness of the ice cap. Wave dislocations and bend points have been observed in radio echoes reflected from the bed. It is suggested that amplitude and phase measurements from a network of sites may be synthesized in order to explore the geometry of the reflecting surface on a fine scale.
\end{abstract}

Résumé. Sondage par écho-radio sensible aux déphasages sur la calotte glaciaire de Devon Island, Canada. Une sonde par écho-radio a été construite qui peut mesurer à la fois l'amplitude et le déphasage des échos-radio. Des expériences avec cet instrument sur la calotte glaciaire de Devon Island dans les Territoires du Nord du Canada ont permis de faire des mesures précises d'amplitude et de phase sur des échos-radio provenant du lit de la calotte. Si ces mesures sont répétées après un certain nombre d'années, les résultats, rapprochés des données sur l'accumulation et le tassement de la neige, pourront être interprétés pour caractériser les changements à long terme de l'épaisseur de la calotte. Des dislocations d'onde et des changements de direction ont été observés dans les échos-radio réfléchis sur le lit. On propose que des mesures d'amplitude et de phase à partir d'un réseau de sites puissent être rassemblées afin d'explorer à échelle fine la géométrie de la surface réfléchissante.

Zusammenfassung. Phasenempfindliche Radar-Echolotungen auf dem Eisschild des Devon Island, Kanada. Es wurde eine Radar-Echosonde gebaut, mit der sowohl die Amplitude wie die Phase von Radar-Echos gemessen werden kann. Bei Versuchen mit diesem Gerät auf dem Eisschild von Devon Island im Kanadischen Nordterritorium wurden Radar-Echos vom Untergrund des Eisschildes nach Amplitude und Phase genau ausgemessen. Wiederholt man diese Messungen nach einigen Jahren, so lassen sich die Ergebnisse in Verbindung mit Daten über die Schneeakkumulation und -setzung als langzeitliche Veränderungen der Dicke des Eisschildes auswerten. Wellenversetzungen und Krümmungspunkte waren in Radar-Echos vom Untergrund zu beobachten. Es wird vorgeschlagen, durch Synthese von Amplituden- und Phasenmessungen über ein Netz von Beobachtungspunkten die Geometrie der reflektierenden Oberfläche grossmasstäbig zu erfassen.

\section{INTRODUCTION}

Radio glaciology has become well established during the past twelve years and a variety of echo-sounding techniques have been developed. We describe here a phase-sensitive radio-echo instrument and a programme of field work carried out with it at the Devon Island ice cap in Canada, during May and June 1976.

The instrument transmits short pulses of radio waves locked in phase with respect to a crystal-controlled oscillator. Radio echoes are received and we observe not only their amplitude as a function of time but also their phase with respect to the continuously running oscillator. We thus record the whole of the information carried by the radio echoes; more conventional echo sounders measure as a function of time the echo amplitude smoothed over a few radio-frequency cycles. Several interesting radio-echo techniques not previously exploited in glaciology are possible with the phase-sensitive radio-echo equipment.

An important objective of our field programme was to carry out the first part of an experiment intended to determine whether, in the long term, the ice cap is growing or reducing in thickness (Nye and others, 1972). Radio echoes were measured repeatedly and precisely at single sites near the crest of the ice cap. Each site was surveyed by theodolite with respect to a local gravity station which is to be maintained for a number of years. Radio-echo spatial fading patterns were recorded locally and measurable markers were buried in the snow. We hope to return to Devon Island in a few years' time, relocate the radio-echo sites and remeasure the echoes. Any significant change in phase will be interpreted in terms of a local change in the thickness of the ice cap (Nye, 1975) and compared with the observations of vertical strain-rate in a nearby bore hole (Paterson, r 976 ). 
Radio echoes from the bed of the Devon Island ice cap were found to be strongly depolarized in comparison with the linearly polarized transmitted wave. Echoing wave trains frequently contained dislocations of the type previously observed in laboratory experiments with pulsed ultrasonic waves (Nye and Berry, 1974). The amplitude and phase of radio echoes were recorded as functions of time over networks of sites. The relative height of the aerial at each point within a network was known so results can, in principle, be combined to synthesize the action of an aerial array of high gain. The beam of this synthetic aerial array can be directed to probe the geometry of the bedrock on a relatively fine scale. We hope to publish the results of this analysis at a later date. The technique of aperture synthesis may, in principle, permit one to observe echoes from the bed of a temperate glacier, which would be obscured by scattering from within the ice when using conventional low-gain aerials.

\section{THE RADIO-EGHO SOUNDER}

Radio-echo sounding through ice has been successful at frequencies from one to several hundred $\mathrm{MHz}$. We chose to operate near $60 \mathrm{MHz}$ as attenuation in ice is low at this frequency, aerials are not inconveniently large, electronic techniques are straightforward, and commercial equipment is readily available.

Figure IA shows a block diagram of the radio-echo system. A crystal-controlled oscillator mounted in a thermoelectrically controlled oven provides a stable reference signal against which phase measurements are made. The oscillator frequency is $59.997 \pm 0.00 \mathrm{I} \mathrm{MHz}$.
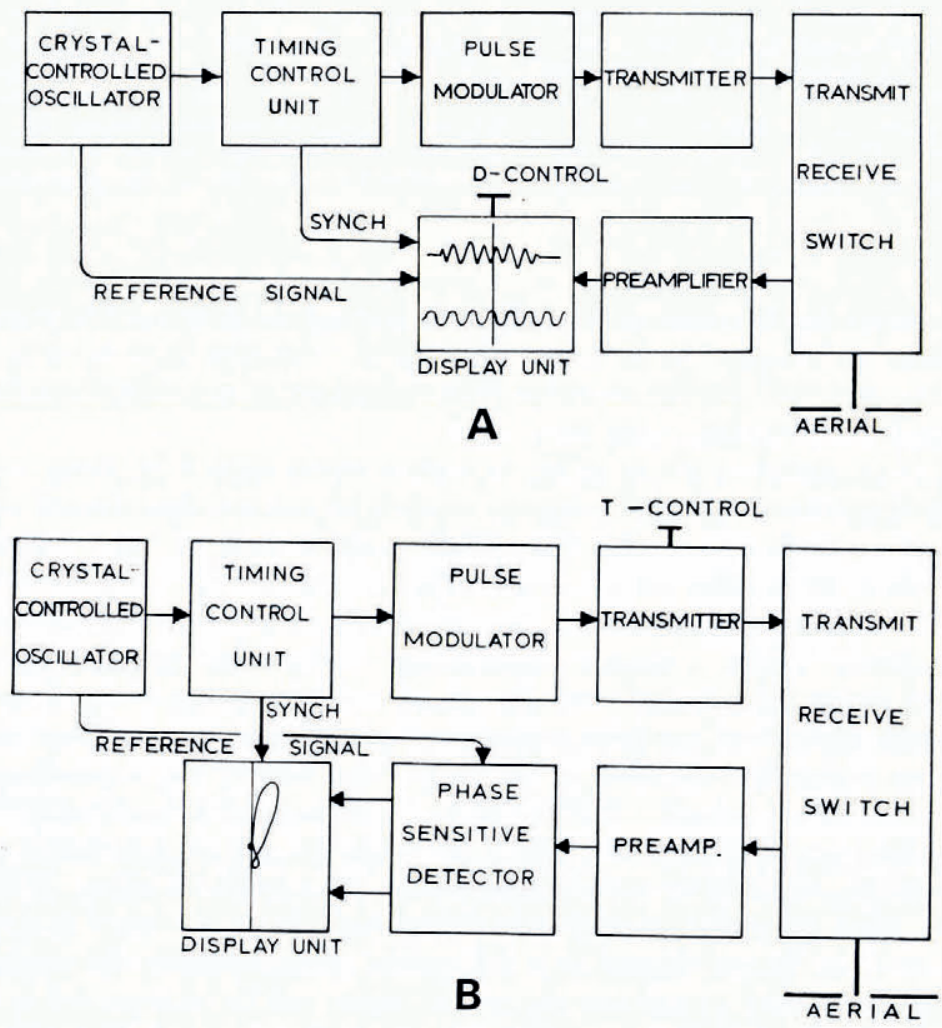

Fig. I. Block diagrams of the phase-sensitive radio-echo sounder. In $A$ the equipment is connected in order to display radio echoes in $A$-scope format. In $B$ the equipment is arranged to display radio-echo signatures in an $X-Y$ format. 
It was measured before and after the field-work season, using an accurate laboratory frequency meter. In the field, the frequency was compared from time to time with a second crystal-controlled oscillator. No significant changes in frequency occurred during the fieldwork season.

The oscillator output drives a timing-control unit which uses emitter-coupled integratedlogic circuitry. Pulses from here synchronize the oscilloscope display and provide a trigger at a pulse-repetition rate of approximately ro $\mathrm{kHz}$. The trigger switches on a fast thyristor in a pulse modulator circuit which drives the pulsed transmitter, a double-beam tetrode of conventional design. The transmitter output is fed through a transmit-receive switch to a wide-band dipole aerial.

The top diagram in Figure 3 shows the envelope of the transmitter output pulse. The amplitude, frequency, and pulse length of this pulse are adjustable. The time at which the transmitter fires, relative to the incoming trigger, can be smoothly and precisely varied over a range of approximately $5^{\circ} \mathrm{ns}$, by a finely calibrated control, which we refer to as the T-control.

Radio echoes are received and pre-amplified by a low-noise, wide-band, linear amplifier of variable gain. Signals may be displayed in A-scope format, with the reference waveform displayed on a second (lower) trace for comparison purposes. From the display we measure the amplitude of echoes and their phase with respect to the displayed oscillator signal, as functions of the delay time, with the echo sounder at rest on the snow surface. The measured phase is determined by the total time taken for signals to travel from the oscillator through the logic and transmitter systems, the aerial, the ice, and the receiver system to the oscilloscope display, in comparison with the time taken for the reference signal to travel from the oscillator to the oscilloscope display.

It is permissible to think in this way of simple paths through the system, with well-defined time intervals for the transmission of signals from point to point, provided that the system is sufficiently free from distortion. During design and construction, care was taken to meet this condition. Each radio-frequency stage has a wide dynamic range and band width. The breakthrough of unwanted signals from one stage to another is reduced by careful shielding and by electrically decoupling the power supply to each stage. Very careful electrical matching throughout the system reduces the multiple-reflection of signals between one stage and the next to an acceptable level. As a further precaution interconnecting cables were labelled, carefully routed, and not used interchangeably.

More precise phase measurement is possible using the phase-sensitive detection system shown in Figure IB. From the reference oscillator, two 6o MHz switching signals are derived which differ in phase by $\pi / 2$. These switching waveforms and the radio-echo signals are fed to a pair of double-balanced mixers. The action of a double-balanced mixer is to transmit the echo signal unchanged during positive half-cycles of the switching signal and to transmit an inverted version of the echo signal during negative half-cycles of the switching signal. Mixer outputs are smoothed in order to filter out radio frequencies. The resulting video-frequency signals are amplified and fed to the $X$ and $Y$ plates of the oscilloscope respectively whilst the trace is simultaneously brightened. With this system the echo causes a signature to be displayed on the screen which characterizes the amplitude and phase structure of the echo. The instantaneous displacement of the spot from the screen centre is proportional to the echo amplitude, the direction of this displacement on the screen is a measure of the echo phase. There is an uncertainty in measuring phase in this way equal to $2 \pi n$ radians where $n$ is an integer, but this uncertainty can be removed by referring back to the A-scope display.

In practice some distortion of the echo signatures arises because the bandwidth of the $\boldsymbol{X}$ channel oscilloscope amplifier is only $4 \mathrm{MHz}$. We reduce systematic errors arising from this by using the $\mathrm{T}$-control on the transmitter. This calibrated control delays the instant at which the transmitter fires and hence rotates the echo signature. We use the T-control to bring that part of the echo which is to be measured, to a vertical fiducial line through the centre of the 
display. We measure the displacement and read the $\mathrm{T}$-control, taking these readings as measurements of the amplitude and phase of the echo at that instant. The amplitude-phase display is an interesting and useful adjunct to the normal A-scope echo display. As the echo sounder moves horizontally over the snow surface the characteristic echo signature changes shape. If, on the other hand, the aerial is raised vertically, the characteristic shape of the signature changes relatively slowly but the signature rotates as a whole about the centre of the screen, one complete rotation occurring as the range increases by half a wavelength.

In principle the phase of a radio-echo signal $40 \mathrm{~dB}$ above noise can be determined with respect to the signal from the crystal-controlled oscillator, with a precision of $\pm 3^{\circ}$. With the A-scope display (Fig. I A), the precision of such a phase measurement is $\pm 30^{\circ}$ and is limited by the precision of the oscilloscope controls. With the phase-sensitive display (Fig. IB), the precision was $\pm 10^{\circ}$ during the experiments at Devon Island. The precision was limited by two unwanted instrumental phenomena which affected the precise time at which the transmitter fired after being triggered. The first was a slow, irregular drift which was attributed to thermal effects and to variations in the output of the supply batteries. A careful experimental technique, which we describe later, was needed to reduce the effects of drift. Secondly, jittering occurred, caused by the switching action of transistorized power convertors in the transmitter. This effect has since been overcome.

\section{The THEORY OF PHASE MEASUREMENTS OF PULSED EchoES}

We have described a radio-echo sounding instrument with which the amplitude and the phase, with respect to a continuously running oscillator, of a radio echo, can be measured as functions of echo delay time. The amplitude and phase, measured in this way, must now be related to the theoretical definitions of time-varying amplitude and phase of a wave train given by Nye and Berry (1974).

Following Nye and Berry, we suppose that the function $\cos \left(-\omega_{0} t\right)$ represents the voltage signal at the terminals of the crystal-controlled oscillator. The transmitter produces a voltage signal at the aerial terminals, $\gamma_{\mathrm{c}}(t)$, which we may regard as being produced by a welldefined process of amplitude and phase modulation carried out upon $\cos \left(-\omega_{0} t\right)$. We may write therefore

$$
\gamma_{\mathrm{c}}(t)=\rho^{\prime}(t) \cos \left(\phi^{\prime}(t)-\omega_{0} t\right)
$$

and note that $\rho^{\prime}(t)$ and $\phi^{\prime}(t)$ contain no frequencies greater than $6 \mathrm{MHz}$ in the present apparatus. Let $\psi_{\mathrm{c}}(t)$ represent the voltage signal at the aerial terminals produced by a radio echo. $\psi_{\mathrm{c}}(t)$ may be regarded as being produced from $\gamma_{\mathrm{c}}(t)$ by well-defined processes of scattering. If we change the voltage signal at the oscillator terminals to $\sin \left(-\omega_{0} t\right)$, and keep the modulation and the scattering processes constant, then the transmitter signal at the aerial terminals can be written $\gamma_{\mathrm{s}}(t)$ and the radio-echo signal at the aerial terminals can be written $\psi_{\mathrm{s}}(t)$. Using complex notation we may write:

$$
\begin{aligned}
\exp \left(\mathrm{j}-\omega_{0} t\right) & =\cos \left(-\omega_{0} t\right)+\mathrm{j} \sin \left(-\omega_{0} t\right), \\
\gamma(t) & =\gamma_{\mathrm{c}}(t)+\mathrm{j} \gamma_{\mathrm{s}}(t), \\
\psi(t) & =\psi_{\mathrm{c}}(t)+\mathrm{j} \psi_{\mathrm{s}}(t)=\rho(t) \exp (\mathrm{j} \chi(t)),
\end{aligned}
$$

$\gamma_{\mathrm{c}}(t), \gamma_{\mathrm{s}}(t), \psi_{\mathrm{c}}(t), \psi_{\mathrm{s}}(t), \rho(t)$ and $\chi(t)$ are all real functions of time and $\rho(t)$ is always positive. We define $\rho(t)$ as the amplitude and $\phi(t)$ as the phase of the radio echo where

$$
\phi(t)=\omega_{0} t+\chi(t) .
$$

(This is a slightly different usage from that of Nye and Berry who refer to $\chi(t)$ as the phase.)

We now define two functions

$$
\begin{aligned}
& X(t)=\rho(t) \cos \phi(t), \\
& Y(t)=\rho(t) \sin \phi(t) .
\end{aligned}
$$


These well-defined, unique functions describe the amplitude and phase structure of the radio echoes. We require to generate voltage signals proportional to $X(t)$ and $Y(t)$ and apply them to the $X$ and $Y$ plates of the oscilloscope. However, a difficulty now appears. $X(t)$ and $Y(t)$ are not, in general, uniquely defined by $\psi_{\mathrm{c}}(t)$ alone, $\psi_{\mathrm{s}}(t)$ is also required. However, only $\psi_{\mathrm{c}}(t)$ is present at the aerial terminals. We shall show that the phase-sensitive detection system in fact generates signals proportional to $X(t)$ and $Y(t)$, subject to certain special conditions.

The inputs to the phase-sensitive detector are essentially $\psi_{\mathrm{c}}(t)$ and $\cos \left(-\omega_{0} t\right)$. The doublebalanced mixers operate to produce two outputs which can be written

$$
\psi_{\mathrm{c}}(t) C\left(\omega_{0}, t\right) \quad \text { and } \quad \psi_{\mathrm{c}}(t) S\left(\omega_{0}, t\right)
$$

where $C\left(\omega_{0}, t\right)$ and $S\left(\omega_{0}, t\right)$ are square waves defined by the equations:

$$
\begin{aligned}
& C\left(\omega_{0}, t\right)=\sum_{n=1}^{n=\infty} \frac{\mathrm{I}}{n} \cos \left(n \omega_{0} t\right), \\
& S\left(\omega_{0}, t\right)=\sum_{n=1}^{n=\infty} \frac{\mathrm{I}}{n} \sin \left(n \omega_{0} t\right),
\end{aligned}
$$

where $n=\mathrm{I}, 3,5, \ldots$. We may write these output functions in terms of $X(t)$ and $Y(t)$ as follows:

$$
\begin{aligned}
\psi_{\mathrm{c}}(t) C\left(\omega_{0}, t\right) & =\rho(t) C\left(\omega_{0}, t\right) \cos \chi(t) \\
& =\rho(t)\left\{\cos \phi(t) \cos \omega_{0} t+\sin \phi(t) \sin \omega_{0} t\right\} C\left(\omega_{0}, t\right) \\
& =\left\{X(t) \cos \omega_{0} t+Y(t) \sin \omega_{0} t\right\} C\left(\omega_{0}, t\right) \\
& =\frac{1}{2} X(t)+\frac{2}{3} X(t) \cos 2 \omega_{0} t+\frac{1}{3} Y(t) \sin 2 \omega_{0} t+\ldots,
\end{aligned}
$$

similarly

$$
\psi_{\mathbf{c}}(t) S\left(\omega_{0}, t\right)=\frac{1}{2} \Upsilon(t)+\frac{2}{3} X(t) \sin 2 \omega_{0} t-\frac{1}{3} Y(t) \cos 2 \omega_{0} t+\ldots .
$$

Sinusoidal terms of angular frequency greater than $2 \omega_{0}$ have not been written down. If $X(t)$ and $Y(t)$ contain no angular frequencies greater than $\omega_{0}$, we may apply the signals $\psi_{\mathrm{c}}(t) C\left(\omega_{0}, t\right)$ and $\psi_{\mathrm{c}}(t) S\left(\omega_{0}, t\right)$ to the input of low-pass filters designed to transmit $\frac{1}{2} X(t)$ and $\frac{1}{2} \Gamma(t)$ and filter out all the other, higher-frequency terms. We do therefore generate signals proportional to $X(t)$ and $Y(t)$ from $\psi_{\mathrm{c}}(t)$ and $\cos \left(-\omega_{0} t\right)$ rather than from $\psi_{\mathrm{c}}(t)$ and $\psi_{\mathrm{s}}(t)$, subject to the condition that $X(t)$ and $Y(t)$ contain no angular frequencies greater than $\omega_{0}$. This condition is met in the present apparatus because $\rho^{\prime}(t)$ and $\phi^{\prime}(t)$ contain no frequencies greater than $6 \mathrm{MHz}$ and $\psi_{\mathrm{c}}(t)$ is produced from $\gamma_{\mathrm{c}}(t)$ by essentially linear scattering processes.

\section{Qualitative observations OF RADIO EGHOES}

We surveyed within a few kilometres of the bore-hole station, near the crest of the Devon Island ice cap, using the echo sounder with a dipole aerial, mounted on a sledge. Echoes from the bed and from within the ice were always present although the latter were small. Echoes from the bed arrived from 3 to $7 \mu \mathrm{s}$ after transmission. They were generally from $\mathrm{I}$ to $3 \mu$ s long, some tens of decibels above noise, and exhibited a richly structured spatial-fading pattern. An A-scope display showed that dislocations were very common: occasionally they were present even in the head of the echo. The phase signatures of echoes from the bed were interesting. As the sledge moved over the snow the signature changed, but not apparently in a completely random fashion. Often, for example, a distinct lobe could be seen rotating about the centre of the display several times before losing its identity. Such lobes are not necessarily in the head of the echo: we occasionally observed two lobes simultaneously rotating in opposite directions. This may be associated with the movement of the sledge relative to major echoing features on the bed. Very often a part of the curve comprising the phase signature sweeps smoothly through the origin of the display. Examination of the A-scope display always revealed that a dislocation corresponded to this event. 
Bend points frequently appear in the phase signature (Fig. 2, position 5). At a bend point the amplitude and phase of the echo remain stationary for a time, which must be longer than the reciprocal of the bandwidth of the system. Consequently bend points are bright parts of the echo signature. As the sledge moves over the snow, a bend point seems to persist for a few metres and then either resolves into a smooth curve (Fig. 2, position 3) or develops into a closed loop, the trace then crossing itself (Fig. 2, position 6).

The signature of a radio echo is never very complicated because the bandwidth of the system limits the rate of change with time of the echo amplitude and phase. It is interesting to observe as the sledge moves along how loops are produced and disappear by the mechanisms of bend points and dislocations (Fig. 2). Both bend points in the signature and dislocations in the wave train appear to be generic features of the spatial fading pattern.

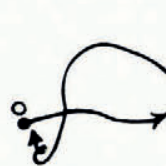

1

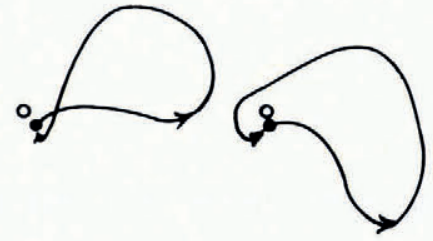

2

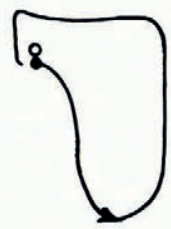

4

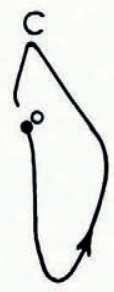

5

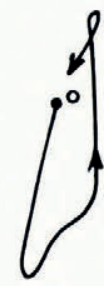

6

Fig. 2. Characteristic signatures of radio echoes observed at six positions spaced approximately o. 3 m apart along a straight line. The origin of the display is at $\bigcirc$ and echo delay time increases along the signature in the direction shown by the arrow. The signatures shown are tracings from photographs of the oscilloscope face. They do not show variations in the line intensity or the details in the tail of the echo. A dislocation occurs between position 2 and position 3. A cusp C at position 5 develops into a loop in position 6 .

\section{The PRecise measurement of Radio echoes}

We describe now our first series of measurements in the long term study of changes in thickness of the Devon Island ice cap. Measurements were made at two sites near the crest of the ice cap several hundred metres south of the bore-hole site. We describe first the experimental method of using the phase-sensitive radio-echo sounder to measure as precisely as possible the time interval between launching a pulse of radio waves and receiving the echo from the bed. Then we discuss supplementary observations.

The radio aerial was a wide-band resonant dipole of adjustable length. It was fed from the transmit-receive switch through a known length of $5^{\circ} \Omega$ coaxial cable. A tuned balun was mounted at the aerial centre. We adjusted the aerial and measured its admittance with a radio-frequency bridge. The admittance was $20 \pm 1 \Omega^{-1}$ at $60 \mathrm{MHz}$ and remained sufficiently constant for our purposes as long as the aerial was at least $0.3 \mathrm{~m}$ above the snow surface. If the aerial approached the snow surface more closely both its admittance and the detailed shape of the radio-echo signature altered significantly. We therefore always mounted the aerial $0.3 \mathrm{~m}$ above the snow surface.

The rate of electrical drift in the equipment was minimized by mounting it in a heated caboose and allowing it to run for half an hour before starting to measure. The caboose stood on a metal sledge but the radio echoes from the bed were not affected by the presence of the sledge as long as the aerial was at least $4 \mathrm{~m}$ in front of it and oriented normal to the sledge runners.

We have emphasized that the measured phase $\phi(t)$ is determined by the time taken for signals to propagate through the electronic equipment as well as by the propagation time through the ice. We therefore compared observations of the radio echoes with observations made upon a standard echo returned from within a long coaxial cable. We also measured the 
transmitter pulse itself by connecting the transmitter output directly through an attenuator to the aerial socket of the transmit-receive switch. This measurement was less precise than was the measurement of radio echoes because some transmitter signal breaks directly through from transmitter to receiver, despite the shielding.

The procedure for measuring signals was as follows. The radio-echo signal was displayed first in A-scope format. The oscilloscope has a control, which we call the D-control, by means of which we can delay the start of the trace. The D-control was calibrated using the crystalcontrolled oscillator. We used the D-control to bring each chosen radio-frequency cycle of the echo in turn to a fiducial mark in the centre of the screen. The D-control reading, the amplitude of the cycle, and the time of day are noted for each chosen cycle. The radio aerial was
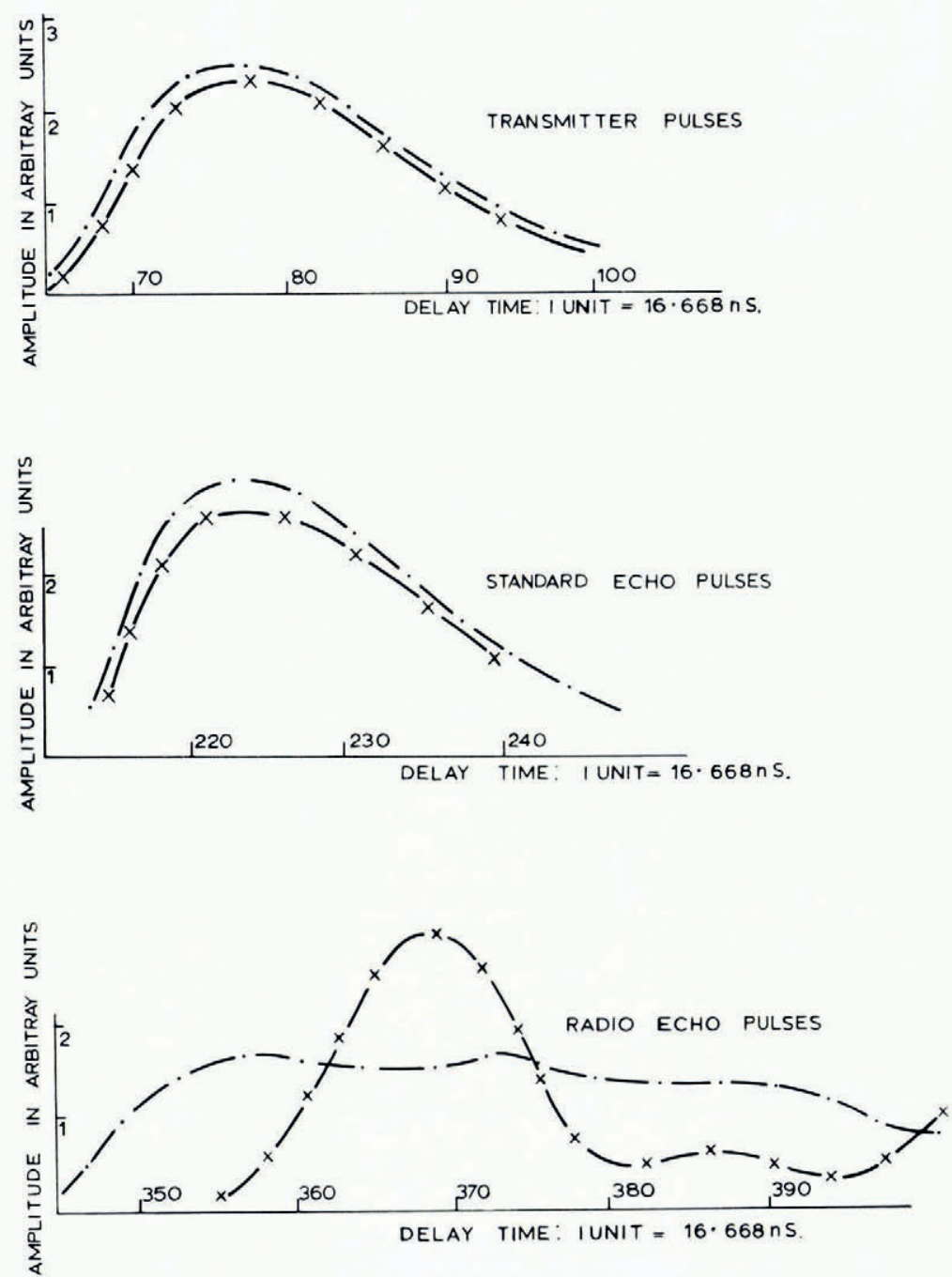

Fig. 3. Data from A-scope displays of transmitter pulses, standard echo pulses obtained with a delay cable, and radio-echo pulses from the bed of the ice cap. Data from site 2 were obtained on 3 June 1976 and are represented by curves drawn through data points. Data from site 3 were obtained on 30 May 1976 and are represented by curves drawn through crosses. All data have been corrected for instrumental drift. Data points and crosses indicate the amplitude and delay time of positive peaks of the radio-frequency signals. The origin of the delay time axis is arbitrary but common to all three graphs. The scale of the amplitude axis is different in the three curves. 


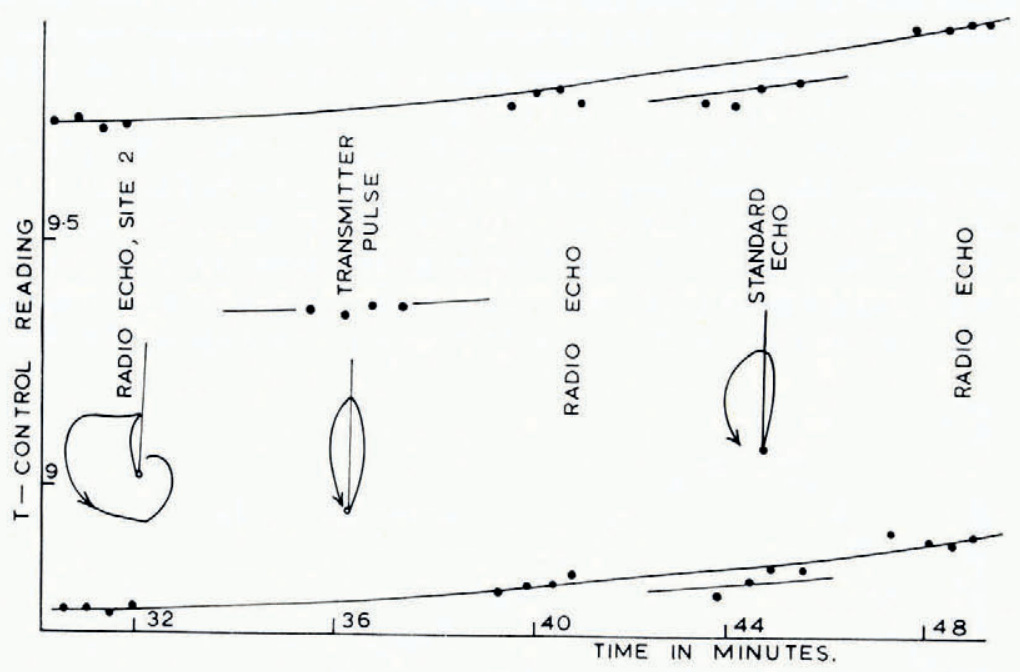

A

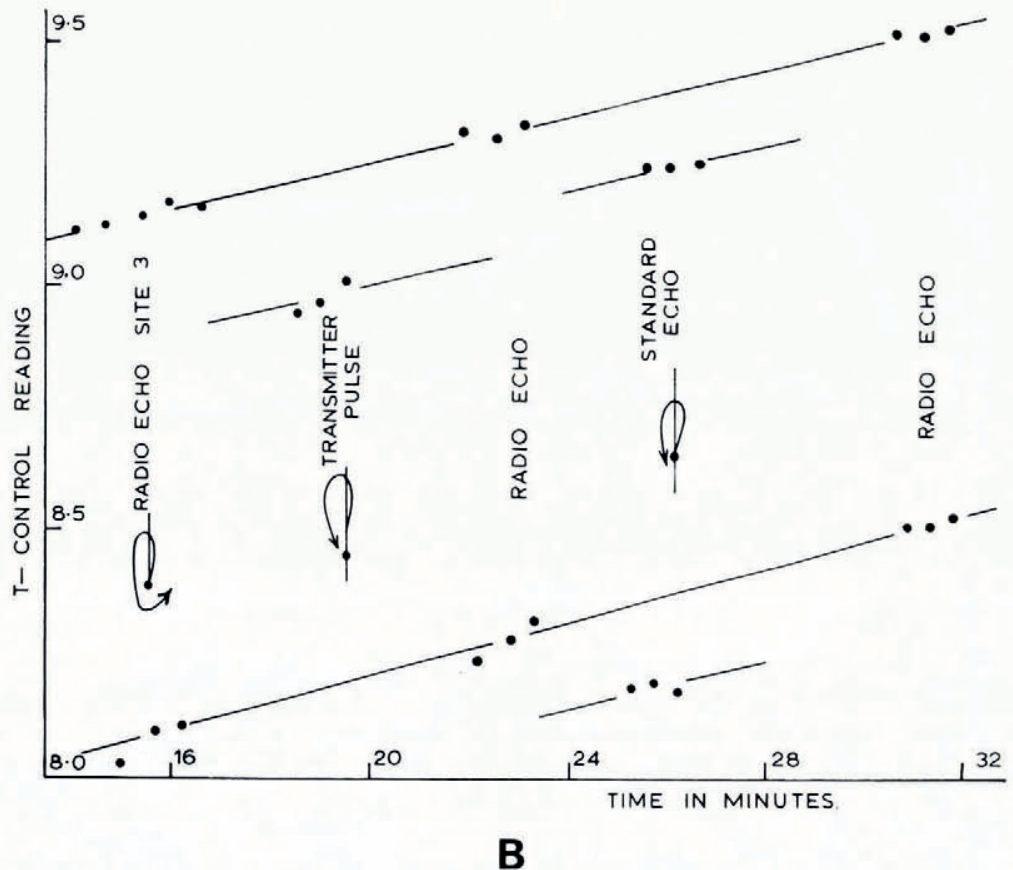

Fig. 4. Samples of measurements made from oscilloscope displays of the signatures of radio echoes, transmitter pulses and standard echoes from delay cables. A represents data from site 2 taken on 3 June $1976, B$ represents data from site 3 taken on 30 May ${ }_{1976}$. Inset sketches show the characteristic signatures correctly oriented with respect to a fiducial line on the oscilloscope screen through the origin of each signature. In B for example, the radio echo was correctly oriented at time I6 min with the transmitter delay control ( $T$-control) set at either 8.10 or 9.17. As the $T$-control setting was increased from 8.10 to 9.17 the signature rotated once, anticlockwise. Instrumental drift accounts for the change of the $T$-control readings with time. 
disconnected and the long coaxial cable connected to the radio-echo sounder in its place. The echo from the end of this cable was measured in the same way as the radio ceho. Then the delay cable was removed and the transmitter pulse measured directly in the same way. Finally we repeated the measurement of the radio echo in order to correct our readings for the small but significant effects of electrical drift during the course of the experiment. Samples of the corrected results are shown in Figure 3. They enable us to calculate the time intervals between the echoes and the transmitter pulse, with a precision of a few nanoseconds.

We improved our measurements of these time intervals by observing the signatures of the three signals. The transmitter pulse and the echo from within the cable produced simple signatures in the form of narrow loops. The radio-echo signature was more complicated but at each chosen site the head of the echo was characterized by a fairly well-defined radial line. The head of the echo had therefore rather constant phase with respect to the crystal-controlled oscillator output. We displayed the echo signature and used the T-control to rotate this radial line one way or the other until it was aligned with the fiducial mark on the oscilloscope screen as shown in Figure 4. We noted the $\mathrm{T}$-control reading and the time of day. We displayed and measured the standard echo from the cable and the transmitter pulse signatures in the same way. This cycle of measurements was repeated, enabling us to eliminate from our results the effects of electrical drift within the equipment. Samples of the results are shown in Figure 4.

We repeated this entire set of measurements on several different days at each of the two sites and found that with care consistent results could be obtained. We intend to repeat these measurements in a few years' time using essentially the same equipment. It will be particularly important to use the same crystal frequency, transmitter pulse shape, and radio aerial, and to duplicate the impedance-matching conditions between transmitter, aerial and receiver input. We must also relocate the sites of our measurements with respect to the bed of the ice cap by means which we describe later. If all this can be satisfactorily achieved, and if we find that radio echoes from the bed are substantially unchanged in form, we hope to interpret our measurements in terms of changes in thickness of the ice cap.

\section{OBSERVATIONS SUPPLEMENTARY TO THE ACGURATE MEASUREMENT OF RADIO ECHOES}

We discuss now some important details relating to the measurements described in the preceding section.

We require to know the electrical length of the coaxial cable which provided the standard echo. The cable was in fact in five sections joined by short coaxial connectors. We measured the physical length $L_{\mathrm{m}}$ of each section with a surveyor's tape. With the echo sounder in its A-scope format we measured the change in the echo delay time produced when one section at a time was removed from the delay cable. Hence we formed an estimate, $L_{\mathrm{r}}$, of the electrical length of each section. A more precise measurement, $L_{\phi}$, of this length was obtained from the echo signatures. Ambiguities of an integral number of half-wavelengths inherent in measuring $L_{\phi}$ are resolved by comparison with $L_{\mathrm{r}}$. An independent measurement, $L_{\mathrm{a}}$, of the electrical length of each section of cable is made by measuring its open circuit impedance at frequencies up to $59.997 \mathrm{MHz}$. The results of these measurements are shown in Table I.

We note that $L_{\phi}$ and $L_{\mathrm{a}}$ agree within experimental error and that field measurements of the total length of the cables agree with these also within experimental error. Comparison of $L_{\mathrm{m}}$ and $L_{\phi}$ shows that the wavelength in the cable is $3.34 \pm 0.0 \mathrm{I} \mathrm{m}$ at $59.997 \mathrm{MHz}$. Values of $L_{\mathrm{r}}$ are about $0.15 \mathrm{~m}$ greater than corresponding values of $L_{\phi}$. This is probably because of a small systematic error in $L_{\mathrm{r}}$ arising from a slight non-linearity in the calibration curve of the D-control, of which we have not been able to take full account. The best estimate at present of the electrical length of the delay cable is $73.18 \pm 0.09$ wavelengths at $59.997 \mathrm{MHz}$. 
TABle I. Electrical and Physical Lengths of Delay-CABle Sections

$L_{\mathrm{m}}$ is the physical length of each section of the coaxial cable used to provide a simulated echo for standardization purposes. $L_{\mathrm{r}}, L_{\phi}$ and $L_{\mathrm{a}}$ are electrical lengths in wavelengths at $59.997 \mathrm{MHz}$. $L_{\mathrm{r}}$ was measured from A-scope echo displays, $L_{\phi}$ from displays of echo signatures and $L_{\mathrm{a}}$ using an admittance bridge.

Cable section I

Cable section 2

Cable section 3

Cable section 4

Cable section 5

Sum of sections

Field measurements of whole cable

\begin{tabular}{|c|c|c|c|}
\hline $\begin{array}{c}L_{\mathrm{m}} \\
\mathrm{m}\end{array}$ & $\begin{array}{c}L_{\mathrm{r}} \\
\text { wavelengths }\end{array}$ & $\begin{array}{c}L_{\phi} \\
\text { wavelengths }\end{array}$ & $\begin{array}{c}L_{\mathrm{a}} \\
\text { wavelengths }\end{array}$ \\
\hline $\begin{array}{l}51.68 \pm 0.03 \\
49.64 \pm 0.03 \\
51.06 \pm 0.03 \\
50.57 \pm 0.03 \\
40.78 \pm 0.03\end{array}$ & 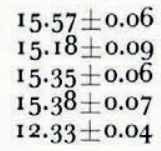 & $\begin{array}{l}\text { I } 5.49 \pm 0.04 \\
\text { I } 4.86 \pm 0.04 \\
\text { I } 5.24 \pm 0.04 \\
\text { I } 5.11 \pm 0.04 \\
\text { I } 2.33 \pm 0.04\end{array}$ & $\begin{array}{l}\text { I } 5.5 \mathrm{I} \pm 0.0 \mathrm{I} \\
\text { I } 4.92 \pm 0.0 \mathrm{I} \\
\text { I } 5.30 \pm 0.01 \\
\text { I } 5.18 \pm 0.0 \mathrm{I} \\
\text { I } 2.29 \pm 0.0 \mathrm{I}\end{array}$ \\
\hline $243.73 \pm 0.07$ & $73.8 \mathrm{I} \pm 0 . \mathrm{I} 5$ & $73.03 \pm 0.09$ & $73.20 \pm 0.02$ \\
\hline - & $73.10 \pm 0.15$ & $73.28 \pm 0.15$ & - \\
\hline
\end{tabular}

Since we hope eventually to measure a change in the thickness of the ice cap, we carried out a brief experiment which approximately simulates the effects of just such a change. At the site chosen for this experiment the radio echo had a rather simple signature dominated by a single large loop, subtending an angle of approximately $50^{\circ}$ at the centre of the oscilloscope screen. The aerial was raised step by step from $0.30 \mathrm{~m}$ to $\mathrm{r} .86 \mathrm{~m}$ above the snow. The signature rotated with only slight change of shape at $110 \pm 20^{\circ}$ per metre change of height. If the bed were a horizontal specular reflector we would expect the rate of rotation to be $144^{\circ} \mathrm{m}^{-1}$. The observed rate appears to be significantly less than this. We explain the result as follows. The aerial has a wide polar diagram and, taking into account the refraction of waves passing from air into ice, we calculate that the bed is illuminated at angles up to $35^{\circ}$ to the vertical. If the bed is rough, the wave vector components of the echo within the ice are also distributed within a vertical cone of semi-angle $35^{\circ}$. It follows that the rate of rotation of the echo signature observed in the air must be less than $144^{\circ}$ per metre change of aerial height. This is in accordance with the observed value $110 \pm 20^{\circ} \mathrm{m}^{-1}$. The experiment emphasizes the need for care in interpreting measured phase changes in terms of changes of aerial height above the bed.

We next consider a point in connection with the way we measured radio echoes, comparing them with a standard echo. This technique places stringent requirements on the impedance matching between the aerial, the delay cable, and the echo sounder. In the following experiment we avoided this difficulty to some extent and displayed the radio echo and a standard echo simultaneously. A second dipole aerial, connected to the long delay cable, was placed $0.30 \mathrm{~m}$ above the snow parallel to the radio-echo aerial. Its presence did not significantly alter the radio echo as long as the two aerials were at least $3.5 \mathrm{~m}$ apart. A new standard echo was thus produced by radiation from the echo sounder which was received by the second aerial, travelled down the delay cable and, after, reflection, returned to the echo sounder by the same path.

We measured the velocity of propagation of radio waves across the snow between the two aerials, by measuring the variation of echo delay-time as a function of the separation of the two aerials. When they were closer together than $3.5 \mathrm{~m}$ the shape of the echo became distorted, with the aerials more than $8.14 \mathrm{~m}$ apart the echo was too small to measure accurately. We found that signals propagated between the aerials at $295 \pm 6 \mathrm{~m} \mu \mathrm{s}^{-1}$.

We compared this new standardization procedure with the earlier technique in which the delay cable was connected directly to the radio-echo sounder. The two methods agreed to within 0.02 wavelengths at $60 \mathrm{MHz}$ if we assume that signals propagated between the aerials at $295 \mathrm{~m} \mathrm{\mu s}^{-1}$ and that the pair of aerials introduced an effective total delay of $2 \times 0.5^{0}$ wavelengths in the signal path. The signature of the echo from the cable in this experiment was very similar in shape to the signature produced when the cable was plugged directly into 
the aerial socket of the transmit-receive switch. These observations confirm that the bandwidth of the aerial system and the impedance matching between the aerial and the echo sounder are adequate for our purposes.

In a similar experiment we connected the far end of the delay cable to the receiver input and were able to measure the velocity of propagation of waves over the snow surface with the

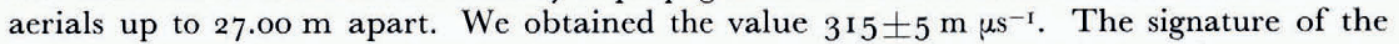
signal in this experiment varied slightly but systematically with the aerial separation, presumably because radiation scattered from the snow or from the coaxial cable contributed significantly to the signal.

We conclude from these studies that a second aerial matched to a delay cable can provide a standard echo which is very useful for calibrating our phase-sensitive radio-echo sounder.

\section{Preparations For fUture MEASURements}

Further radio-echo measurements at Devon Island may give useful information about changes in the thickness of the ice cap. We are prepared therefore to attempt to return to the two sites where precise measurements of echoes were made, relocating them with respect to the fixed bed of the ice cap. Our preparations are described below.

Members of the Polar Continental Shelf Project, Canadian Department of Energy, Mines and Resources, intend to maintain a gravity survey station on the ice cap for a number of years. The geographical position of this station is known. A ground survey was carried out under the direction of Dr R. G. Oakberg to relate the gravity station to the two radio-echo experimental sites. Neither stars nor fixed landmarks were visible, and Devon Island lies close to the North Magnetic Pole so a standard bearing was established by repeated extrameridian observations of the sun. The observations also yielded values of the refraction
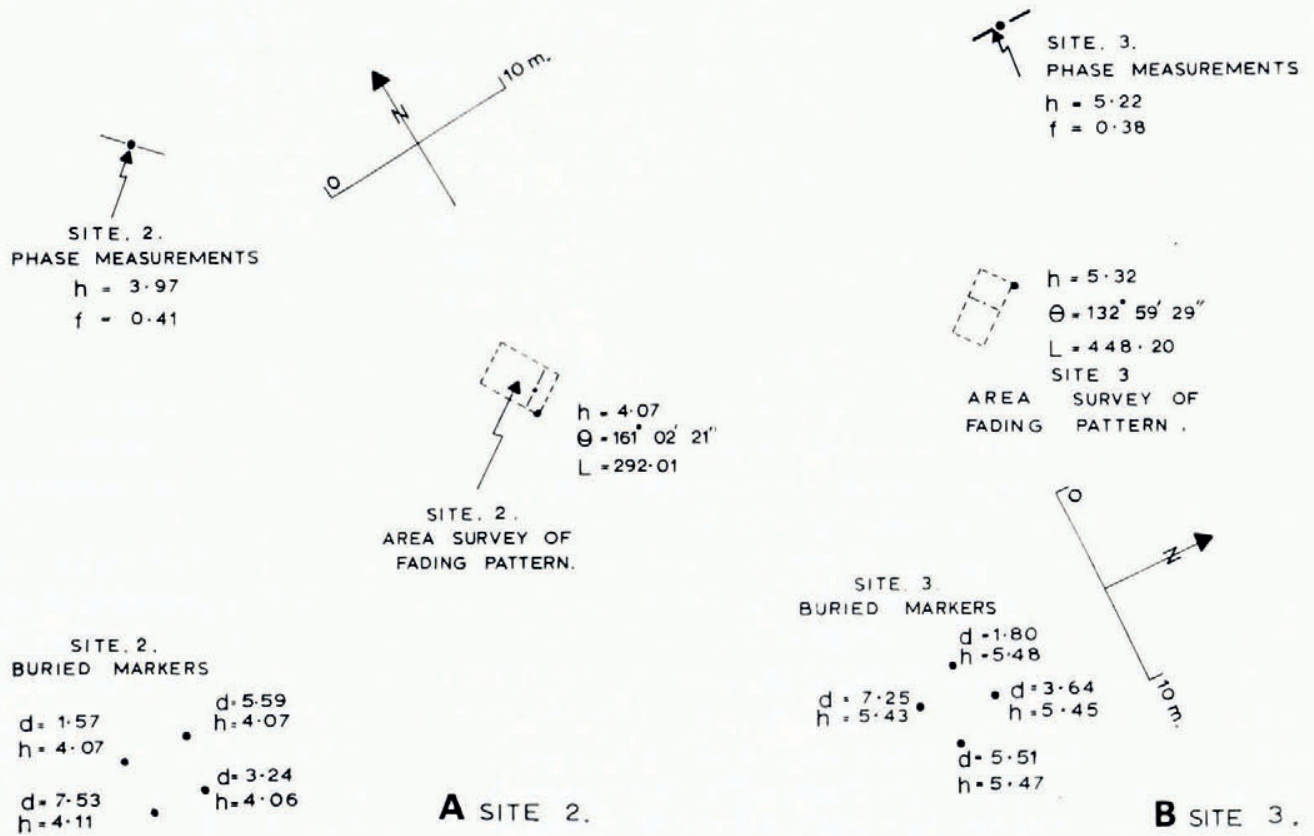

Fig. 5. Maps showing the radio-echo sounding experimental sites 2 and 3. All distances are in metres, measured from inscribed wooden markers set in the snow surface. $h$ is the height, $L$ the distance and $\theta$ the bearing of the markers with respect to a bench mark at the permanent gravity station. $d$ is the depth of buried markers below the snow surface and $f$ is the height of the aerial centre above the snow surface. 
coefficient and the station latitude. The station longitude was checked approximately using watch time. During the ground survey, bearings relative to the established standard bearing were measured by theodolite, relative heights were measured with $\pm \mathrm{I} \mathrm{cm}$ precision by levelling and lengths were measured by tachymetry to $\pm 50 \mathrm{~cm}$. Figure 5 presents the results of the ground survey.

Near each radio-echo site, an area $3 \mathrm{~m}$ by $\mathrm{I} .5 \mathrm{~m}$ was marked out. The spatial fading pattern of radio echoes within this area was recorded by photographing echoes at lattice points $0.15 \mathrm{~m}$ apart. On a future visit to Devon Island we plan to relocate these areas, approximately, by repeating the ground survey from the gravity station. We shall then repeat the observation of the spatial fading patterns. Comparing the new and the original fading patterns, we expect to relocate, with respect to the bed of the ice cap, the positions on the horizontal plane of the sites 2 and 3 , where precise radio-echo phase measurements were made. (This type of experiment has been carried out nearby by Doake and others. They report that in this region, spatial fading patterns are stable over a number of years (Doake and others, I976).) We shall repeat the precise phase measurement of the radio echoes at sites 2 and 3 .

As a result of these measurements we expect, in effect, to re-establish a three-dimensional coordinate frame of reference, fixed with respect to the bed rock.

Several markers were buried in the snow near each radio-echo site. Small weights were attached to steel wires of known length, the weights were heated and then dropped into holes from 2 to $8 \mathrm{~m}$ deep. When the weights were securely frozen in place, we measured the lengths of wire protruding above the snow surface. The holes were covered and the wires secured to a central staff.

We know the present position of these markers, and the position of the snow surface, with respect to the frame of reference fixed to bedrock. We hope in future to re-locate the markers and the new snow surface, with respect to this same frame of reference re-established by radioecho means. The horizontal movement of the markers will indicate the mean horizontal velocity of the firn with respect to the bedrock. The vertical displacement of the snow surface will indicate what change in thickness of the ice cap has occurred during the intervening years. The surface displacement, however, is very sensitive to the particular value of the mean accumulation rate during this interval and so gives a poor indication of long-term change in thickness, which would be of general interest. A better measure is provided by comparing the vertical displacement of the buried markers with accumulation records from stratigraphic studies. The full theory of this is complicated and has been discussed elsewhere in some detail (Nye, 1975).

The precision with which the displacement of the markers can be measured will, in practice, probably be limited by how accurately we can re-establish the frame of reference with respect to the bed, using the radio-echo sounder. This depends upon instrumental accuracy, upon the long-term stability of the reflecting bedrock surface, and upon fluctuations in the vertical profile of the velocity of radio waves in the ice and firn.

We can measure the phase of echoes with respect to the crystal-controlled oscillator with $10^{\circ}$ precision and so can compare the radio echo and standard echo with a precision of ${ }_{1}^{\circ}$. If our standard cable and aerial matching are unaltered, we may therefore re-establish the vertical axis of the frame of reference in the future, with an instrumental precision of $0.10 \mathrm{~m}$. We estimate that fluctuations in the vertical wave velocity profile in the firn may necessitate a small but significant correction to the position of the frame of reference based upon the stratigraphic profile. (We hope meanwhile to improve the precision of the instrument and of our measurements of the electrical length of the standard cable in future.) In the horizontal plane we expect to re-establish the frame of reference with precision of $0.03 \mathrm{~m}$. The measurements of Doake and others ( 1976 ) suggest that the bedrock echoes may be sufficiently stable to permit this precision. 


\section{SUMmary}

We have shown that it is possible to use a phase-sensitive radio-echo sounder to set up a three-dimensional coordinate frame of reference fixed relative to the bed of an ice cap, precise to a small fraction of a wavelength and independent of visible landmarks. This makes possible absolute measurements of changes in the thickness of the ice cap with time. The phase-sensitive system also permits the study of dislocations and bend points in radio echoes. Dislocations provide useful markers in the echoing wave field. We suggest using aperture synthesis techniques in radio glaciology to probe the geometry of the reflecting surface on a fine scale or, possibly, to permit echo sounding through temperate ice. A high-gain or focussing synthetic aerial array would help discriminate against the clutter echoes which often obscure the bed-rock echo, when conventional techniques are used.

\section{Acknowledgements}

This research was supported by a research grant from the Natural Environmental Research Council. Support in the field was provided by the Polar Continental Shelf Project of Canada, and in particular by Dr W. S. B. Paterson and Dr R. M. Koerner. The principles of our research were suggested by experiments using an ultrasonic analogue apparatus. In developing the radio-echo sounder, help was provided by Dr R. G. Sale, Dr P. S. Aplin and Mr L. Wallis. The work proceeded under the general inspiration and guidance of Professor J. F. Nye whom we thank particularly for advice on matters of theory and principle.

MS. received 27 October 1976 and in revised form 19 November 1976

\section{REFERENCES}

Doake, C. S. M., and others. 1976. A further comparison of glacier velocities measured by radio-echo and survey methods, by C. S. M. Doake, M. Gorman and W. S. B. Paterson. Journal of Glaciology, Vol. 17, No. 75, p. $35-38$.

Nye, J. F. 1975. Deducing thickness changes of an ice sheet from radio-echo and other measurements. Fournal of Glaciology, Vol. 14, No. 70, p. 49-56.

Nye, J. F., and Berry, M. V. 1974. Dislocations in wave trains. Proceedings of the Royal Society of London, Ser. A, Vol. 336 , No. 1605 , p. $165-90$.

Nye, J. F., and others. 1972. Measuring the change in thickness of the Antarctic ice sheet, by J. F. Nye, M. V. Berry and M. E. R. Walford. Nature, Physical Science, Vol. 240, No. 97, p. 7-9.

Paterson, W. S. B. 1976. Vertical strain-rate measurements in an Arctic ice cap and deductions from them. Journal of Glaciology, Vol. 17, No. 75, p. $3^{-12 .}$ 